\title{
Diagnosis of Developmental Dysplasia of the Hip Using Sound Transmission in Neonates
}

\author{
Nicolas Padilla-Raygoza1, Diana Medina-Alvarez ${ }^{1}$, Ma Laura Ruiz-Paloalto², \\ Teodoro Cordova-Fraga ${ }^{3}$, Modesto Antonio Sosa-Aquino ${ }^{3}$, Aaron Huetzin Perez-Olivas ${ }^{3}$ \\ ${ }^{1}$ Department of Nursing and Obstetrics, Division of Health Sciences and Engineering, Campus Celaya \\ Salvatierrra, University of Guanajuato, Celaya, Mexico \\ ${ }^{2}$ Department of Clinical Nursing, Division of Health Sciences and Engineering, Campus Celaya Salvatierrra, \\ University of Guanajuato, Celaya, Mexico \\ ${ }^{3}$ Department of Engineering Physics, Division of Engineering Science, Campus Leon, University of Guanajuato, \\ Leon, Mexico \\ Email: raygosan@ugto.mx
}

Received 15 August 2014; revised 30 September 2014; accepted 15 October 2014

Copyright (C) 2014 by authors and Scientific Research Publishing Inc.

This work is licensed under the Creative Commons Attribution International License (CC BY).

http://creativecommons.org/licenses/by/4.0/

c. (i) Open Access

\section{Abstract}

The developmental dysplasia of the hip disease is in $1 \%$ of newborns, and it is a risk factor for dislocation of the hip; only 1 from 7000 newborns develops dislocation of the hip. Newborns were selected from public and private hospitals in Celaya, Guanajuato. Parents were asked to sign informed consent. Clinical maneuvers were applied for diagnosis of developmental dysplasia of the hip, on three consecutive occasions, two by the same investigator and the third by a different observer: Ortolani, Barlow, Piston, Galeazzi, Peter Baden, the comparative sound transmission test, and comparative sound transmission with extension/flexion test were applied. The diagnosis was confirmed with ultrasound of hip, technique Graf, I healthy hip, II functionally immature, III subluxation, and IV dislocation. Sample size was 8 affected hips and 56 healthy hips. Kappa for intra observer and inter observer reliability were measured; the validity was measured by sensitivity, specificity, positive and negative predictive values, using the ultrasound diagnosis as the gold standard. The sample consisted of 78 neonates hips with female's predominance. With comparative sound transmission test was obtained Kappa intra observer 0.80, Kappa inter observer 0.93, sensitivity $45.45 \%$, specificity $96.27 \%$, positive predictive value $66.67 \%$ and negative predictive value 91.49\%; with comparative sound transmission with extension/flexion, was $0.83,0.92$,


help better diagnose developmental dysplasia disease of the hip.

\section{Keywords}

Sound Transmission, Newborns, Developmental Dysplasia of Hip

How to cite this paper: Padilla-Raygoza, N., Medina-Alvarez, D., Ruiz-Paloalto, M.L., Cordova-Fraga, T., Sosa-Aquino, M.A. and Perez-Olivas, A.H. (2014) Diagnosis of Developmental Dysplasia of the Hip Using Sound Transmission in Neonates. Health, 6, 2510-2516. http://dx.doi.org/10.4236/health.2014.618289 


\section{Introduction}

The developmental dysplasia of the hip (DDH) is common throughout the world; in particular, about $1 \%$ of births in Mexico present with DDH, although evolution to dislocation hip, the rate only gets to be in 1:7000 in live births [1].

The DDH may be due to maternal hormones, large for gestational age, presentations with extension of lower limbs, poor obstetric practices during birth and postnatal life by deficiencies in the form of transfer and swaddling of infant [2]-[4]. The DDH is classified into physiological immaturity, subluxation, luxable and dislocation; the clinical diagnosis is made with clinical maneuvers, as Ortolani, Barlow, Piston, Galeazzi, Peter Baden or limitation to abduction, but these maneuvers only detect subluxation, luxable or dislocation of the hips [2] [4], being undiagnosed infants or infants with physiological immaturity, which is a risk factor to evolve to subluxation, luxable or dislocation. To confirm the diagnosis, in neonates, the use of ecography with Graf technique is recommended, and the uses of X-ray are not recommended for children under eight weeks after birth, as misleading by the lack of ossification of the femoral head.

Fernandez [5] stated that $17 \%$ of affected children were diagnosed by the doctor and the other was diagnosed for the family, usually after the second half of first year of life of the infant. Figueroa et al., reported that $75 \%$ of macrosomic infants who did not have positive clinical data, showed ecographic data of DDH [1].

The diagnosis usually does the physician and the orthopedic implements treatment [3], but requires that all health personnel in contact with infants, be involved in the diagnosis, because if this treatment is done on an early life, i.e. before 3 months of age, the prognosis for hip function is excellent with full recovery, but if the diagnosis is made when the infant starts walking which darkens the prognosis, treatment is usually surgery [3].

The clinical maneuvers as Ortolani, Barlow and Peter Baden are used as clinical methods for diagnosis of $\mathrm{DDH}[3]$.

A clinical method described by Stone et al., [6] for the diagnosis of the DDH is comparative tests of the sound transmission, based on bone sound transmission properties that allow the detection of the physiological immaturity, subluxation, luxable or dislocation of the hip, where a tuning fork and stethoscope [2] [4] [6] is used.

The sounds compared transmission tests detect the physiological immaturity, subluxation, luxable or dislocation of hip, but they are totally subjective and dependent hearing examiner and the training that he received [2] [4] [6].

Sensitivity was $27.27 \%$ with comparative sound transmission test and $86.36 \%$ with extension/flexion, well above the 5.11\%, 2.27\% and 5.68\% of the Ortolani, Barlow and Peter Baden, respectively, in Mexican infants [4]. Neither Stone et al., [6] nor Padilla et al. [2] [4] calculated reliability of testing sound transmission.

The aim was to identify the validity and reliability of the transmission of sound to the diagnosis of DDH in neonates.

\section{Subjects and Methods}

\subsection{Bioethics Committee}

The protocol was reviewed and approved by Research Committee of Division of Health Sciences and Engineering, Campus Celaya Salvatierra University of Guanajuato and Research Committee and Bioethics Committee of Hospital General Celaya, of Ministry of Health from Guanajuato State.

\subsection{Study Design}

It was a diagnosis study, based in hospitals.

\subsection{Study Population}

Newborns from Celaya, Guanajuato, born in public and private hospitals.

\subsection{Sampling}

Stratified random sampling was performed by hospitals and one public hospital has the highest number of births, with approximately 6000 annually, followed by the second public hospital with 800 annual births and all private 
hospitals are approximately 3000 births annually. Newborns were selected according to the proportional number of each institution.

\subsection{Selection of Participants}

\subsubsection{Inclusion Criteria}

Infants born in the two public hospitals and two private hospitals in the city of Celaya, Gto, aged between 4 and 28 days after birth, both sexes, whose parents agreed to participate in the study by signing the informed consent. Male and female newborns between 4 and 28 days old, whose parents agreed to participating in the study through written consent.

\subsubsection{Exclusion Criteria}

Infants with congenital dislocation of hip (atypical).

\subsection{Sample Size}

Assuming a sensitivity of $90 \%$ of the compared sound transmission test with extension/flexion and sensitivity Ortolani maneuver $6 \%$, with a ratio of affected/unaffected 7 , with $95 \%$ confidence and $90 \%$ power, the minimum sample size is 8 affected hips and 56 healthy hips (Epidat 3.1, 2006, Xunta from Galicia and Pan American Health Organization).

\subsection{Study Procedures}

Parents of infants were explained the objectives of the study and were asked to sign informed consent, and then were applied tests Ortolani, Barlow, Piston, Galeazzi, Peter Baden and limitation of abduction; also were applied compared sound transmission test and sound transmission with extension/flexion, all twice by the same investigator and a third by another investigator, blinded to the results of first researcher. It was performed ecography of hips with Graf technique to corroborate the diagnosis, using it as gold standard.

\subsection{Variables}

\subsubsection{Measuring of Exposures}

Sociodemographic variables such as age, gender, place of residence, weight and height at birth, current weight and height were obtained.

After application of standard clinical tests, it were applied the compared sound transmission test, which is that the infant was placed in the supine position with the lower extremities in extension and adduction. The tuning fork from 256 cycles/second is placed vibrating on his left kneecap and stethoscope is placed on the symphysis pubis, perceiving sound; the tuning fork is then placed on the patella on the left and the sound is perceived, compared to the sound of the left side. If the sound is lower in either side, that means the hip is affected. In case of bilateral affected hip, the sound will be the same in both sides.

Subsequently, the test sound transmission with extension/flexion, where the patient was placed in supine position, with the pelvic limbs in extension and adduction and the vibrating tuning fork is placed on the patella on the left and stethoscope on the symphysis pubis, the sound is perceived and hip flexion was $90^{\circ} \mathrm{C}$, the sound is perceived and compared to the sound with the limb in extension; If the sound intensity increases to the flexion, the hip is affected. The same procedure is repeated on the right side.

\subsubsection{Measuring Results}

Developmental dysplasia of hip, dichotomy qualitative variable, the loss of the relation of the structures of the hip measured with the Graf technique ultrasound with static and dynamic tests measuring $\alpha$ and $\beta$ angles [9].

- Healthy hip-An ultrasound classification at Graf I, where the acetabulum covers $50 \%$ or more of the femoral head; $\alpha>60^{\circ}$ and $\beta>55^{\circ}$.

- Functionally immature hip-ultrasound is rated Graf II; $\alpha 44^{\circ}-59^{\circ}$ and $\beta 55^{\circ}-77^{\circ}$.

- Subluxation and dislocation-ultrasound classification of Graf III; $\alpha<43^{\circ}$ and $\beta>77^{\circ}$ [7]-[9]. Clinical diagnosis alone, has a little value [10]. 


\subsection{Data Management}

The subjects of the study had no personal identifiers; they were identified using an alpha numeric code. Electronic files of the databases have no personal identifiers.

\subsection{Statistical Analysis}

Descriptive statistics were used for sociodemographic variables.

Intra observer Kappa (1st and 2nd measurements of all tests) and inter observer (1st and 3rd measurements) were calculated for to know the reliability of standard clinical tests and testing sound transmission.

Validity, reliability and predictive values of clinical maneuvers and comparative testing sound transmission was calculated using the ecographic diagnosis as the gold standard.

For all statistical analysis STATA $13.0^{\circledR}$ (STATA Corp. College Station, TX, USA) was use.

\section{Results}

The sample consisted of 78 newborns, whose categorical socio demographic characteristics are shown in Table 1 , which demonstrate that dominated women living in urban areas.

Table 2 shows the socio demographic characteristics of quantitative variables of the members of the sample.

For the reliability of standard clinical tests and sound transmission tests are shown in Table 3, reporting that the intra-observer reliability for maneuver Ortolani, Barlow, Piston, Peter Baden were perfect, and transmission sound and sound transmission with extension/flexion, was very good with Kappa 0.8 for both maneuvers. For the intra-observer reliability for Ortolani, Barlow were regular with Kappa 0.53 and 0.59 , respectively, were perfect for maneuvers Piston and Peter Baden (Kappa 1.00 for both), and very good compared sound transmission and transmission compared to extension/flexion tests (Kappa 0.93 and 0.92, respectively).

The sensitivity was low for Barlow, Piston, Ortolani and Peter Baden maneuvers, improving with compared sound transmission test and even better for sound transmission with extension/flexion (45.45\% and $72.73 \%$, respectively); specificities showed greater than $90 \%$ for all values maneuvers; positive predictive values were

\begin{tabular}{|c|c|c|c|c|}
\hline \multirow{3}{*}{ Variable } & \multicolumn{4}{|c|}{ Developmental dysplasia of the hip } \\
\hline & \multicolumn{2}{|c|}{ Positive } & \multicolumn{2}{|c|}{ Negative } \\
\hline & $\mathrm{n}$ & $\%$ & $\mathrm{n}$ & $\%$ \\
\hline \multicolumn{5}{|l|}{ Gender } \\
\hline Male & 6 & 25.29 & 18 & 29.51 \\
\hline Female & 11 & 64.71 & 43 & 70.49 \\
\hline \multicolumn{5}{|l|}{ Residence } \\
\hline Urban & 12 & 70.59 & 43 & 70.49 \\
\hline Suburban & 3 & 17.65 & 12 & 19.67 \\
\hline Rural & 2 & 11.76 & 6 & 9.84 \\
\hline \multicolumn{5}{|c|}{ Family background of DDH } \\
\hline Yes & 1 & 5.88 & 9 & 14.75 \\
\hline No & 16 & 94.12 & 52 & 85.25 \\
\hline \multicolumn{5}{|l|}{ Family affected by DDH } \\
\hline Mother & & & 2 & 3.28 \\
\hline Brother, sister & 1 & 5.88 & 2 & 3.28 \\
\hline Cousin & \multicolumn{2}{|c|}{0} & 1 & 1.63 \\
\hline Uncle & \multicolumn{2}{|c|}{0} & 4 & 6.56 \\
\hline Nobody & 16 & 94.12 & 52 & 85.25 \\
\hline
\end{tabular}

Source: Forms from study. 
Table 2. Quantitative sociodemographics characteristics of newborns, Celaya, $2013(n=78)$.

\begin{tabular}{cccc}
\hline Variable & & Measures & \\
\cline { 2 - 4 } & Range & Mean & $\mathrm{S}^{\mathrm{a}}$ \\
\hline Age (days) & 4 to 28 & 13.5 & 7.78 \\
Birth weight $(\mathrm{kg})$ & 2.2 to 4.2 & 3.17 & 0.43 \\
Stature at birth $(\mathrm{cm})$ & 44 to 55 & 49.86 & 2.17 \\
Current weight $(\mathrm{kg})$ & 2.27 to 5.10 & 3.51 & 0.61 \\
Current stature $(\mathrm{cm})$ & 47 to 59 & 51.60 & 2.54 \\
\hline
\end{tabular}

${ }^{\mathrm{a}} \mathrm{S}=$ standard deviation. Source: Forms from study.

Table 3. Reliability of clinical maneuvers to diagnosis of developmental dysplasia of hip, Celaya, $2013(\mathrm{n}=78)$.

\begin{tabular}{ccc}
\hline \multirow{2}{*}{\begin{tabular}{c} 
Klinical maneuver \\
\cline { 2 - 3 } Krtolani
\end{tabular}} & \multicolumn{2}{c}{ Kappa } \\
Intra-observer $(95 \% \mathrm{CI})$ & Inter-observer $(95 \% \mathrm{CI})$ \\
\hline Barlow & $1.00(1.00$ to 1.00$)$ & $0.53(0.17$ to 0.89$)$ \\
Piston & $1.00(1.00$ to 1.00$)$ & $0.59(0.22$ to 0.95$)$ \\
Peter Baden & $1.00(1.00$ to 1.00$)$ & $1.00(1.00$ to 1.00$)$ \\
$\begin{array}{c}\text { Sound compared } \\
\text { transmission test }\end{array}$ & $1.00(1.00$ to 1.00$)$ & $0.93(0.83$ to 1.00$)$ \\
$\begin{array}{c}\text { Sound transmission with } \\
\text { extension/flexion }\end{array}$ & $0.80(0.63$ to 0.97$)$ & $0.92(0.82$ to 1.00$)$ \\
\hline
\end{tabular}

Source: Forms from study.

good for Barlow, Peter Baden, Ortolani, sound transmission tests and the best was to Piston with 100\% (Table 4). This can be due clinical maneuvers only detect subluxation or dislocation but sound transmission test detect since physiologically immature hip.

Ecographic diagnoses were 21 affected hips (14.10\%) and 134 healthy hips (85.90\%). Of the 21 affected hips, 20 were Graf II, and 1 was Graf III.

\section{Discussion}

The sample was representative of the population of newborns from Celaya, Guanajuato, because it included infants of the main hospitals in the city.

The sample was selected from neonates 4 - 28 days of life, due to the trauma of delivery. There may be many false positives with Ortolani and Barlow maneuvers; between 3 and 4 days after birth, the infant was stabilized systems, significantly reducing false positives.

The reliability of clinical maneuvers and testing sound transmission was not measured in previous studies [2] [4] [6], which is something important that is obtained in this study. The intra observer reliability is better than inter observer reliability. The researcher, who conducted the third measurement of clinical maneuvers, was a nurse who received training in the application of clinical maneuvers and sound transmission test and confirmed that she performed maneuvers precisely.

The inter observer reliability was half compared with the intra observer reliability, although piston and Peter Baden remained with perfect reliability, and for comparative tests was superior sound transmission to 0.90 (Table 3); this may be because the first researcher had more experience than the second researcher in the application of clinical maneuvers. 
Table 4. Validity of clinical maneuvers to diagnosis of developmental dysplasia of hip, Celaya, 2013 ( $\mathrm{n}=78$ ).

\begin{tabular}{|ccccc}
\hline \multirow{2}{*}{ Clinical maneuver } & \multicolumn{4}{c}{ Validity } \\
\cline { 2 - 5 } Ortolani & Sensitivity (\%) & Specificity (\%) & Predictive value + (\%) & Predictive value - (\%) \\
Barlow & 22.73 & 98.51 & 71.43 & 88.59 \\
Piston & 13.64 & 98.51 & 60.00 & 87.42 \\
Peter Baden & 13.64 & 100.00 & 100.00 & 87.58 \\
Sound compared transmission test & 31.82 & 97.76 & 70.00 & 99.73 \\
Sound transmission with extension/flexion & 75.45 & 96.27 & 66.67 & 91.49 \\
\hline
\end{tabular}

Source: Forms from study.

The clinical maneuvers are commonly used to diagnose the DDH, only detecting cases of subluxation, luxable and dislocation, so that their sensitivity and positive predictive values were expected to be low, as shown in Table 4, unlike to sound transmission tests that allow even detect physiologically immaturity and all forms of DDH.

Padilla et al., in a sample of 104 neonates and infants Mexicans, reported a sensitivity of $72.7 \%$ with sound transmission test and $74.4 \%$ for testing sound transmission with extension/flexion [2]; as results on the sensitivity of the compared sound transmission test, $45.45 \%$ in this study, is very low compared to that reported by Padilla et al.; this may be due to the sound transmission test which evaluates both hips at the same time and bilateral cases are reported as unaffected hips, because the sound will be the same for both hips.

In another study of Padilla et al., in 150 Mexican infants, a sensitivity of sound transmission test of $27.27 \%$ [4], was much lower than that reported in this study, possibly because they had more bilateral cases in the current sample of infants.

The validity of the usual clinical maneuvers for clinical diagnosis of DDH and for testing sound transmission is shown in Table 4.

The sound transmission tests do not distinguish between physiological immaturity, subluxation or dislocation of the hip.

The advantages of sound transmission for diagnosis of DDH are high sensitivity and specificity; it depends on the hearing capacity of researcher; it has low cost and is easy to apply. The disadvantage is the need for training for researchers.

The compared sound transmission and sound transmission with extension/flexion tests, are a useful tool for the diagnosis of DDH. They do not replace the usual clinical maneuvers, but complement them.

It should be useful to develop an objective device based on sound transmission for the diagnosis of DDH.

\section{Acknowledgements}

The authors thank the Council of Science and Technology of Guanajuato State for the grant GTO-2011-C04164448 for this study and also, Support of Research and Post grade Office from the University of Guanajuato for its support for this study.

\section{References}

[1] Figueroa-Ferrari, R.C. and Padilla-Raygoza, N. (1994) Congenital Dislocation of the Hip in the Newborn Macrosomic. Ultrasonographic Aspects. Revista Médica del IMSS, 32, 277-279.

[2] Padilla, N. and Figueroa, R.C. (1992) Diagnosis of Congenital Hip Dislocation, through Comparative Sound Transmission. Revista Mexicana de Pediatría, 59, 149-151.

[3] Padilla, N. (2013) Developmental Dysplasia of the Hip. In: Martinez, R., Ed., Martinez Health of Children and Adolescents, 7th Edition, El Manual Moderno, Mexico, 1513-1517.

[4] Padilla, N. and Figueroa, R.C. (1996) Sound Transmission Tests in the Diagnosis of Congenital Dislocation of the Hip in the Neonate. Revista Mexicana de Pediatría, 63, 265-268. 
[5] Fernandez, E. (1989) Congenital Hip Dislocation: Reduction with Modified Straps Pavlik Children One Year of Age. Rev Mex Ortop Traumatol, 3, 30-34.

[6] Stone, M., Richardson, J. and Bennet, G. (1987) Another Clinical Test for Congenital Dislocation of the Hip. Lancet, 1, 954-955. http://dx.doi.org/10.1016/S0140-6736(87)90296-0

[7] Siegel, M.J. (2004) Ultrasound of the Musculoskeletal and Circulatory Systems. In: Siegel, M.J., Ed., Pediatrics Ecography, Marban Libros SL, Madrid, 629.

[8] Dimeglio, A. (1991) Conenital Dislocation of the Hip. In: Daily Pediatric Orthopedics, Masson Sauramps Medical, Barcelona, 278-304.

[9] Arti, H., Mehdinasab, S.A. and Arti, S. (2013) Comparing Results of Clinical versus Ultrasonographic Examination in Developmental Dysplasia of Hip. Journal of Research in Medical Sciences, 18, 1051-1055.

[10] Kowalczyk, B., Felus, J. and Kwinta, P. (2005) Developmental Dysplasia of the Hip: The Problems in the Diagnosis Process in Our Own Experience. Medycyna Wieku Rozwojowego, 9, 395-406. 
Scientific Research Publishing (SCIRP) is one of the largest Open Access journal publishers. It is currently publishing more than 200 open access, online, peer-reviewed journals covering a wide range of academic disciplines. SCIRP serves the worldwide academic communities and contributes to the progress and application of science with its publication.

Other selected journals from SCIRP are listed as below. Submit your manuscript to us via either submit@scirp.org or Online Submission Portal.
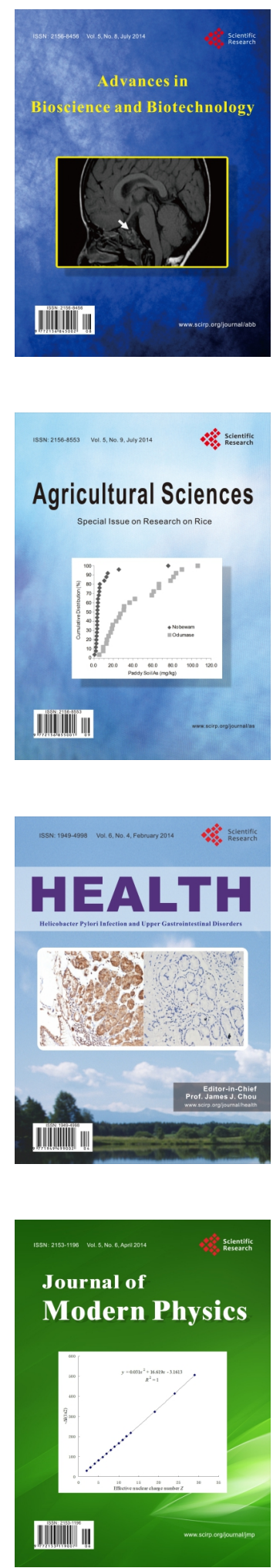
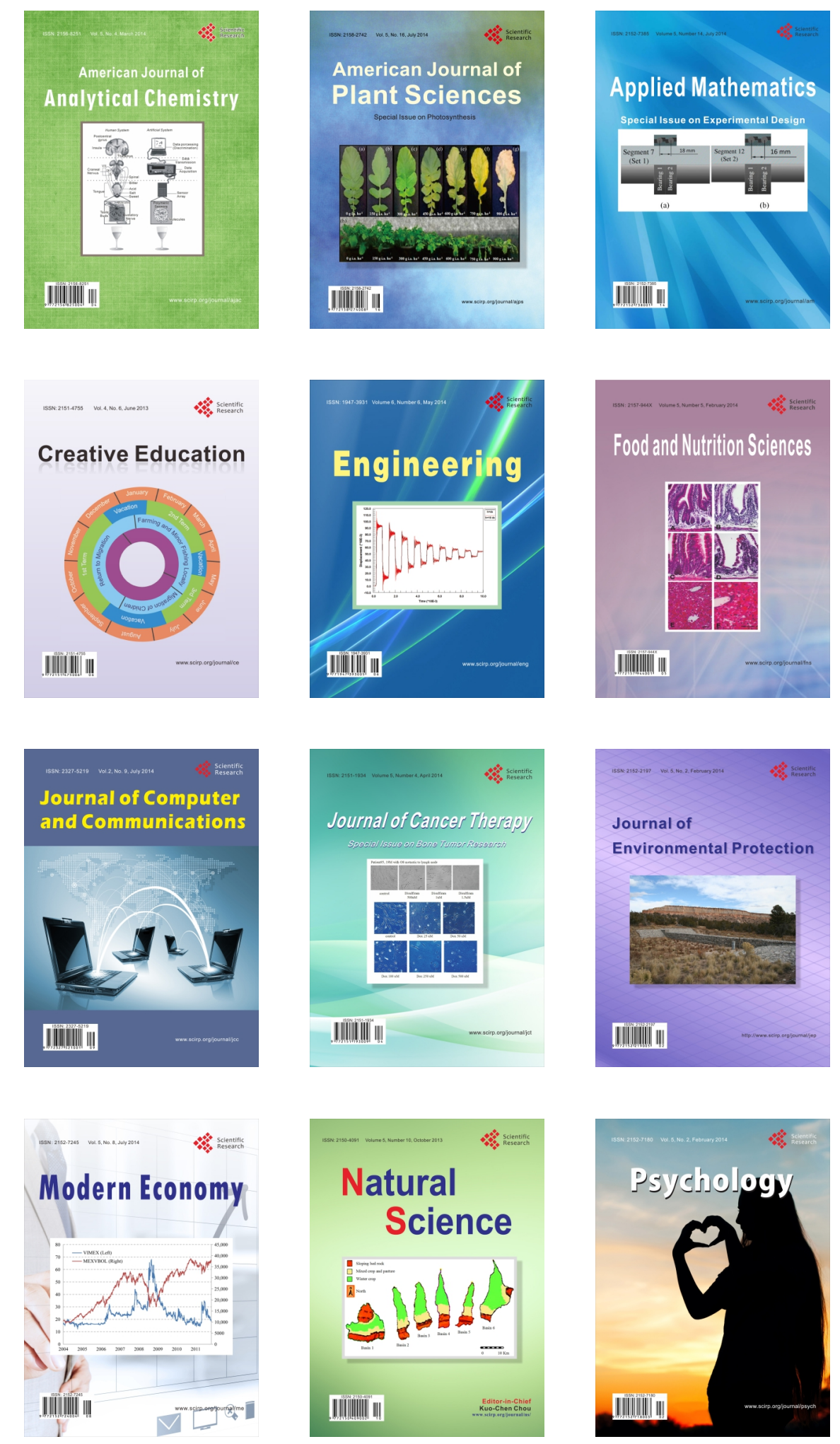